\title{
Serological characterisation of Ureaplasma urealyticum strains by enzyme-linked immunosorbent assay (ELISA)
}

\author{
H TURUNEN, P LEINIKKI, ELLI JANSSON \\ From the Institute of Biomedical Sciences, University of Tampere, Tampere, Finland
}

SUMMARY A modification of enzyme-linked immunosorbent assay (ELISA) was developed for the serological characterisation and identification of strains of Ureaplasma urealyticum. The eight recognised human serotypes of $U$ urealyticum and antisera produced against them were used as reference for the evaluation and standardisation of the method. The serological profile illustrating reactions of antigen with homologous and heterologous antisera was specific and reproducible for each serotype. The homologous reaction was always very prominent but some cross-reactivity was seen, most clearly between serotypes 2 and 5 . The method was found to be suitable for serological typing of clinical isolates of $U$ urealyticum because of rapid and simple technical procedure, good reproducibility of the results and economical consumption of antisera and other reagents.

The serological typing of clinical isolates of Ureaplasma urealyticum may be an important approach in establishing the aetiological role of $U$ urealyticum in pathological conditions of man. Tests used so far have limitations due to complex technical procedures and difficulties in standardisation of the test results. At least eight serotypes have been reported by methods such as growth inhibition, ${ }^{1}$ metabolic inhibition, ${ }^{2}$ and indirect immunofluorescence. ${ }^{3}$ By using a mycoplasmacidal test, Ureaplasma strains have been divided further ${ }^{4}$ and recent studies have indicated that as many as 15 serotypes may exist. ${ }^{5} 6$

We have developed ELISA for various immunological studies in our laboratory and describe here an application which can be used for serological characterisation of Ureaplasma strains isolated from patients. It is technically simple and seems to give a characteristic serological profile for the different serotypes. As the reference in our study we used eight Ureaplasma serotypes and the corresponding antisera as described by Black. ${ }^{1}$ ?

\section{Material and methods}

\section{ORGANISMS}

Reference strains of the eight recognised serotypes of Ureaplasma urealyticum ${ }^{7}$ were obtained in lyophilised form from Dr MC Shepard, Naval
Regional Medical Centre, Camp Lejeune, North Carolina, USA. Clinical strains were isolated from urethral specimens of male and female patients with urethritis and arthritis.

\section{CULTURE MEDIA}

Standard fluid medium $10-\mathrm{B}^{8}$ was used for primary cultivation of the type strains and the urethral specimens. Subcultures were done on differential agar medium A-7.9 Fluid medium U-9,10 supplemented with L-cysteine hydrochloride to a final concentration $0.01 \%$ (U-9B), was used for the production of antigens for the ELISA test.

\section{PREPARATION OF ANTIGENS}

Antigens from the reference strains were prepared by inoculating a three-litre volume of U-9B medium with $30 \mathrm{ml}$ of an overnight culture of each strain. The cultures were incubated at $+37^{\circ} \mathrm{C}$ for $18-20 \mathrm{hr}$. The organisms were harvested by centrifugation in a Sorvall RC-5 centrifuge at $15000 \mathrm{rpm}$ for $60 \mathrm{~min}$. The pellets were resuspended in phosphate-buffered saline (PBS) pH 7.2 and pooled, washed twice with PBS and finally resuspended in $30 \mathrm{ml}$ of PBS. The suspension was sonicated with a MSE sonicator for one minute and stored at $-70^{\circ} \mathrm{C}$ in $1 \mathrm{ml}$ aliquots.

Antigens from clinical isolates were prepared by using a modified U-9B medium, supplemented with $5 \%$ (vol/vol) newborn calf serum instead of normal horse serum. A $0.5 \mathrm{ml}$ volume of the primary culture 
was inoculated into $30 \mathrm{ml}$ volume of modified U-9B medium and after incubation at $+37^{\circ} \mathrm{C}$ for $18-20 \mathrm{hr}$ the organisms were collected by centrifugation in a Sorvall RC-5 centrifuge at $15000 \mathrm{rpm}$ for $30 \mathrm{~min}$. Without further washing the pellet was resuspended in $15 \mathrm{ml}$ of carbonate-bicarbonate buffer $\mathrm{pH} 9.6$ sonicated and used for sensitising polystyrene cuvettes.

\section{PREPARATION OF ANTISERA}

Two albino rabbits $(3 \mathrm{~kg})$ were used for immunisation with each of the eight type strains. For primary immunisation $1 \mathrm{ml}$ of antigen $(0.5 \mathrm{mg}$ of protein) emulsified with equal volume of complete Freund adjuvant was injected subcutaneously into each rabbit at four different sites. After 14 days each rabbit received a booster of $0.5 \mathrm{ml}$ of antigen $(0.25 \mathrm{mg}$ of protein) intravenously. After 10 days animals were exsanguinated. Sera were stored at $-20^{\circ} \mathrm{C}$.

\section{ELISA METHOD}

Tests were carried out in disposable polystyrene nine-microcuvette blocks (Finnpipette-Labsystems Oy, Helsinki, Finland). All antigens were diluted in carbonate-bicarbonate buffer $\mathrm{pH} 9 \cdot 6$. Amounts $(250 \mu \mathrm{l})$ of diluted antigen were added to each cuvette and incubated overnight at $+37^{\circ} \mathrm{C}$. After incubation they were washed three times with PBS pH 7.2 containing $0.5 \%$ (vol $/ \mathrm{vol}$ ) Tween 20 and rinsed with distilled water.

Antisera were diluted in PBS containing $1 \%(\mathrm{wt} / \mathrm{vol})$ bovine serum albumin, $0.05 \%$ (vol/vol) Tween-20 and $10 \%$ (vol/vol) normal horse serum. Portions $(200 \mu \mathrm{l})$ of diluted antiserum was incubated in each cuvette at $+37^{\circ} \mathrm{C}$ for $60 \mathrm{~min}$. The washing procedure was as before.

Alkaline phosphatase conjugated antirabbit IgG (Orion Diagnostica Oy, Helsinki, Finland) was used as a conjugate: $200 \mu \mathrm{l}$, diluted in PBS with $1 \%$ (wt/vol) bovine serum albumin and $0.05 \%$ (vol/vol) Tween-20 was incubated at $+37^{\circ} \mathrm{C}$ for $90 \mathrm{~min}$.

After washing, $200 \mu$ l of $p$-nitrophenylphosphate (Sigma Co, St Louis, USA), $1 \mathrm{mg} / \mathrm{ml}$, diluted in $\begin{array}{llll}\text { diethanolamine- } \mathrm{MgCl}_{2} \text {-buffer } & \mathrm{pH} & \mathbf{1 0} & \text { (Orion }\end{array}$ Diagnostica Oy, Helsinki, Finland) was incubated at $+37^{\circ} \mathrm{C}$ for $30 \mathrm{~min}$ and the reaction stopped by adding $400 \mu$ l of $0.15 M \mathrm{NaOH}$.

The optical absorbances were measured through the bottoms of the cuvettes with a specially designed nine-channel spectrophotometer (FP-9, Labsystems Oy, Helsinki, Finland) at a wavelength of $405 \mathrm{~nm}$. Three parallel determinations for each antiserum were run and the arithmetic mean value was used to calculate the ratios between heterologous and homologous reactions.

\section{Results}

The reference serotype 8 , Ureaplasma strain 960 (CX8), ${ }^{7}$ was used to study the optimal conditions for the test procedure.

\section{ANTIGEN CONCENTRATION}

Solutions of different antigen concentrations were used to sensitise the polystyrene cuvettes. The homologous serotype 8 antiserum, and the heterologous serotype 6 antiserum were used in ELISA to characterise the sensitised cuvettes. The results are presented in Fig. 1. There is an almost linear correlation between the uptake of serotype 8 antiserum and the antigen concentration within the range from $6 \mu \mathrm{g} / \mathrm{ml}$ to $0.6 \mu \mathrm{g} / \mathrm{ml}$ of antigen protein. The best specificity was obtained at a concentration of 2 $\mu \mathrm{g} / \mathrm{ml}$. The linearity was lost and the specificity decreased at higher and lower dilutions of antigen.

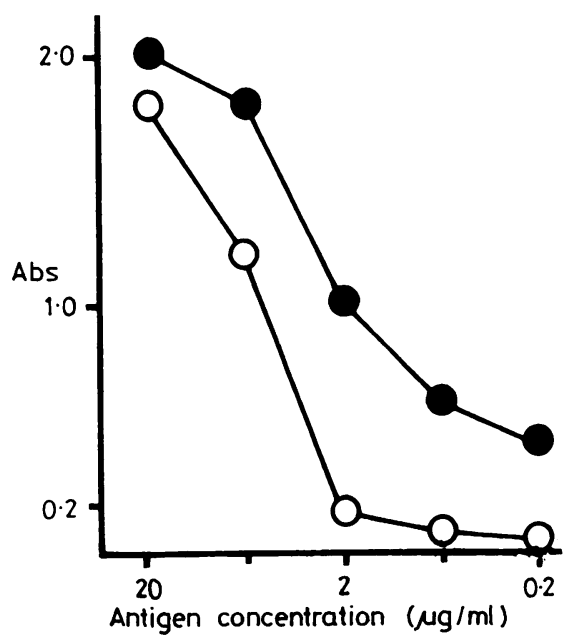

Fig. 1 Absorbance curves for homologous serotype 8 antiserum (0-0) and heterologous serotype 6 antiserum ( $\bigcirc-\bigcirc)$ tested with Ureaplasma serotype 8 antigen at different antigen concentrations.

\section{ADDITION OF NORMAL HORSE SERUM INTO}

THE DILUENT

Initially the hyperimmune sera showed relatively high background and low specificity obviously due to antibodies against horse serum components which were included in the immunising antigen suspensions. To reduce this, different concentrations of horse serum were applied into the diluent used for sera in the ELISA test. Addition of horse serum had a drastic effect, and the best difference between homologous and heterologous reaction was obtained with $10 \%(\mathrm{vol} / \mathrm{vol})$ of normal horse serum in the serum diluent (Fig. 2). 


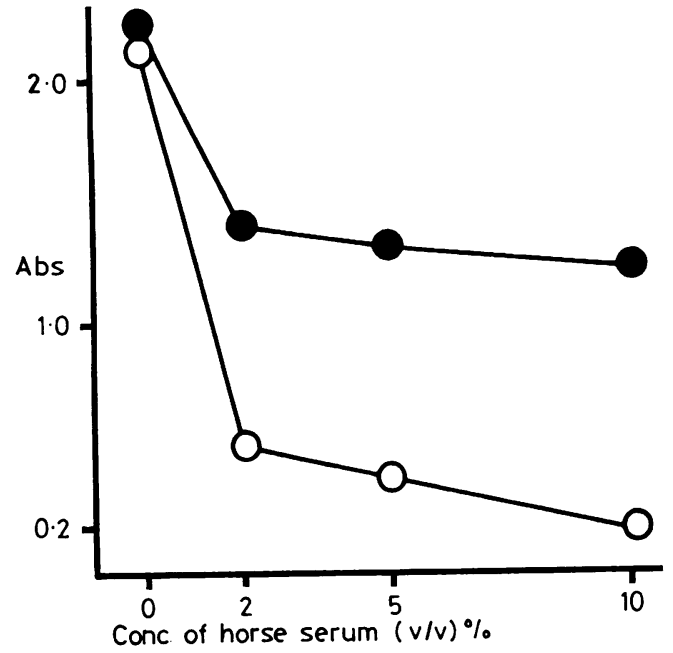

Fig. 2 Effect of normal horse serum added into the antiserum diluent. Absorbance values for homologous serotype 8 antiserum (-O) and heterologous serotype 6 antiserum ( $\bigcirc-\bigcirc)$ tested with Ureaplasma serotype 8 antigen.

\section{SERUM DILUTION}

Optimal serum dilutions were determined by testing serial dilutions from $10^{-1}$ to $10^{-5}$. The optimal difference between homologous and heterologous antiserum was obtained at the serum dilution $10^{-3}$ (Fig. 3). The linear part of the curve for the homologous antiserum was obtained at the serum dilutions from $10^{-2}$ to $10^{-4}$. A slight prozone effect was observed at low serum dilutions (data not shown).

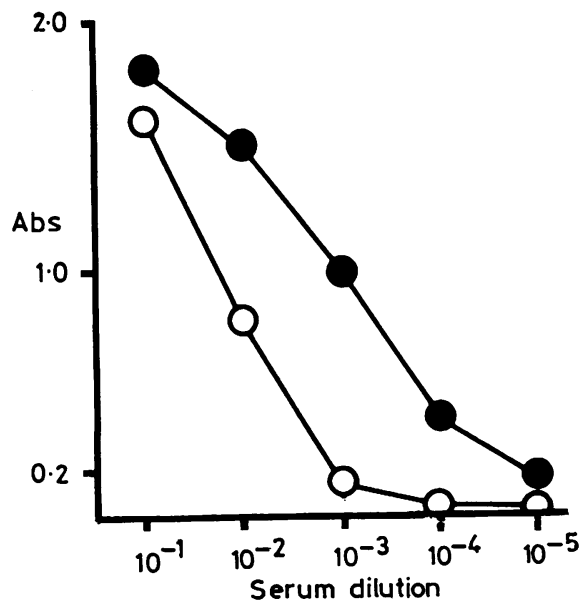

Fig. 3 Absorbance curves for homologous serotype 8 antiserum (O-O) and heterologous serotype 6 antiserum $(\bigcirc-\bigcirc)$ tested in serial dilutions from $10^{-1}$ to $10^{-5}$ with Ureaplasma serotype 8 antigen.
REPRODUCIBILITY OF TEST RESULTS

Serotype 8 antigen was tested in five independent tests performed on different days by using the homologous and two heterologous antisera, antiserum 7 and 3. The results are shown in the Table. The results are expressed as the ratio of absorbance readings of heterologous $v$ homologous reaction. This ratio for antiserum 7 varied between 0.24 to 0.30 and the calculated interassay variation was $6 \%$. For antiserum 3 the ratio was between 0.04 to 0.06 with interassay variation of $2 \%$.

Interassay variation of five independent assays of Ureaplasma serotype 8 antigen by using homologous and two heterologous (types 3 and 7) antisera. The figures indicate the ratio between heterologous and homologous reactions, and the variation $(V)$ is the maximal difference between these tests

\begin{tabular}{|c|c|c|c|c|c|c|}
\hline \multirow{3}{*}{$\begin{array}{l}\text { Antiserum } \\
\text { against } \\
\text { serotype }\end{array}$} & \multicolumn{6}{|c|}{ Ratio between heterologous and homologous reactions } \\
\hline & \multicolumn{5}{|c|}{ Test No } & \multirow{2}{*}{$\begin{array}{l}\text { Variation } \\
(V)\end{array}$} \\
\hline & 1 & 2 & 3 & 4 & 5 & \\
\hline $\begin{array}{l}8 \\
7 \\
3\end{array}$ & $\begin{array}{l}1 \cdot 0 \\
0.24 \\
0.04\end{array}$ & $\begin{array}{l}1 \cdot 0 \\
0.26 \\
0.05\end{array}$ & $\begin{array}{l}1.0 \\
0.30 \\
0.04\end{array}$ & $\begin{array}{l}1.0 \\
0.25 \\
0.06\end{array}$ & $\begin{array}{l}1 \cdot 0 \\
0 \cdot 28 \\
0 \cdot 04\end{array}$ & $\begin{array}{l}-\overline{6 \%} \\
2 \%\end{array}$ \\
\hline
\end{tabular}

SEROLOGICAL CHARACTERISATION OF REFERENCE STRAINS OF Ureaplasma urealyticum BY ELISA

The serological profiles of the eight reference strains as characterised by homologous and heterologous antisera are presented in Fig. 4.

The height of each column represents the ratio between absorbance readings of each heterologous antiserum and the homologous antiserum. The serological profiles were found to be completely reproducible and characteristic for each individual serotype.

The homologous reaction was always very prominent when compared with heterologous reactions. For example serotype 1 antigen gave a distinctive reaction with type 1 antiserum and only minimal cross-reactivity with heterologous antisera. Serotype 2 antigen also gave a prominent homologous reaction but in addition a clearcut cross-reaction with type 5 antiserum. A "reverse" pattern was observed with serotype 5 antigen which reacted also with type 2 antiserum. Serotype 8 antiserum reacted significantly also with type 4 and, to a lesser extent, also with type 7 antigens.

\section{SEROLOGICAL CHARACTERISATION OF}

CLINICAL ISOLATES

Clinical isolates from patients with urethritis and arthritis were studied by using the same antisera 


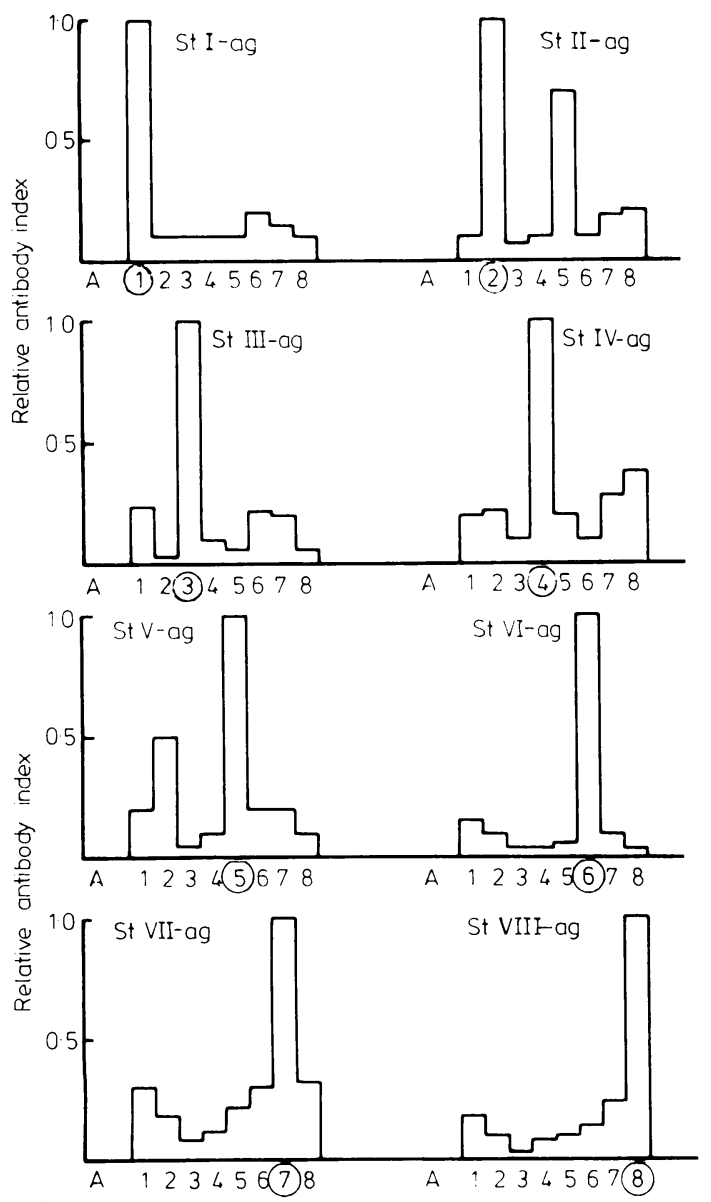

Fig. 4 Serological profiles for eight recognised serotypes of Ureaplasma urealyticum as determined by using ELISA. The height of individual columns represents a ratio between absorbance values for heterologous reaction and homologous reaction.

as above. Thirty strains tested showed characteristic profiles indicating their serotypes. Twelve of these isolates showed serological profiles identical with serotype 3 and nine were identical with serotype 6 . Two isolates had serological characteristics identical with serotype 1 and another two identical with serotype 4 . Serotypes 2,5 and 8 were represented each by one isolate. Two isolates had profiles indicating a mixture of more than one serotype. One was a mixture of serotypes 2 and 8 and the other of serotypes 1 and 6 . This was confirmed by comparing these profiles with profiles from artificial mixtures of the corresponding serotypes.

\section{Discussion}

Ureaplasma urealyticum was first isolated from the urethral discharge of a man suffering from nongonococcal urethritis (NGU) ${ }^{11}$ and since then ureaplasmas have been studied both in this disorder and related infections. Results of isolation studies have been conflicting but recent studies based on the use of differential antibiotics ${ }^{1213}$ and on the inoculation of human volunteers ${ }^{14}$ have proved Ureaplasma urealyticum to be a human pathogen and a cause of urethritis. Ureaplasmas can also be isolated from apparently healthy subjects which may reflect differences in the pathogenicity of various strains.

The human Ureaplasmas form a serologically heterogeneous group consisting of at least eight different serotypes. ${ }^{7}$ Clinical isolates have been serologically typed to find out whether a particular serotype is associated with the disease..$^{15-17}$ No such association has been found regularly but the number of types isolated is still relatively small. Shepard and Lunceford tested 338 strains of Ureaplasma urealyticum by using a modified growth inhibition method. ${ }^{8}$ Serotype 4 was most frequently associated with NGU and some other disorders of the genitourinary tract.

The methods for serotyping have certain limitations. The growth inhibition test is highly specific but quite insensitive and requires large volumes of potent antisera. The metabolic inhibition test is sensitive but growing organisms are used, as in the growth inhibition test, and a careful arrangement of test conditions is necessary. The indirect immunofluorescence test is sensitive and quite specific but the interpretation of results is liable to be inaccurate and variable because the intensity of fluorescence is estimated microscopically by subjective criteria.

The ideal method for serotyping strains of Ureaplasma urealyticum should have a high specificity and sensitivity with economical consumption of antisera and other reagents. The method should also be rapid and simple in order to be suitable for typing of large numbers of isolates. The reproducibility of the results should be good and reliable. Our application of ELISA seems to meet most of these demands.

Because of the high sensitivity only $30 \mathrm{ml}$ of Ureaplasma culture is needed for the preparation of the antigen to be characterised. The consumption of antisera is also low: $10 \mu \mathrm{l}$ of each antiserum is required for one complete test. The consumption of enzyme-conjugated antirabbit immunoglobulin is economical because of the high dilutions that can be used. The measurement of the reactions with a spectrophotometer improves accuracy and objectivity in the final results.

The use of low immunogen doses and a short immunisation period was found to be optimal for 
the production of highly specific antisera as recommended by Kenny. ${ }^{18}$ In addition, horse serum components may contaminate the immunogens resulting in formation of antibodies against these proteins. The use of calf serum instead of horse serum in growth media for typing clinical isolates eliminates part of this problem. The addition of horse serum into the antiserum diluent finally makes the test very specific and sensitive.

In general, the homologous reactions were prominent when compared to cross-reactions, demonstrating that antigenic differences between the strains are clear enough to justify the serological classification. Nevertheless, some marked crossreactions were observed. Serotypes 2 and 5 seemed to share antigens. This has been noted by other methods. ${ }^{1}$ Also types 4,7 , and 8 possibly share a common antigenic component. It will be of interest to see whether new profiles will be seen among clinical isolates suggesting antigenic compositions not compatible with the known serotypes.

Mixed cultures of Ureaplasma serotypes in clinical specimens have been reported. ${ }^{17}$ So far our preliminary data suggest that the ELISA method could also detect these mixed strains in clinical isolates.

\section{References}

${ }^{1}$ Black FT. Modification of the growth inhibition test and its application to human T mycoplasmas. Appl Microbiol 1973;25:528-33.

${ }^{2}$ Purcell RH, Taylor-Robinson D, Wong D, Chanock RM. Color test for the measurement of antibody to $\mathrm{T}$ strain mycoplasmas. J Bacteriol 1966;92:6-12.

${ }^{3}$ Black FT, Krogsgaard-Jensen A. Application of indirect immunofluorescence, indirect haemagglutination and polyacrylamide-gel electrophoresis to human $T$ mycoplasmas. Acta Pathol Microbiol Scand [B] 1974;82: 345-53.

${ }^{4}$ Lin J-SL, Kendrick MI, Kass EH. Serologic typing of human genital $T$-mycoplasmas by a complementdependent mycoplasmacidal test. J Infect Dis 1972;126: 658-63.

${ }^{5}$ Lin J-SL, Kass EH. Fourteen serotypes of Ureaplasma urealyticum (T-mycoplasmas) demonstrated by the complement-dependent mycoplasmacidal test. Infection $1980 ; 4: 152-5$.
${ }^{6}$ Robertson JA, Stemke GW. Modified metabolic inhibition test for serotyping strains of Ureaplasma urealyticum (T-strain mycoplasma). J Clin Microbiol 1979;6:673-6.

${ }^{7}$ Shepard MC, Lunceford CD, Ford DK, et al. Ureaplasma urealyticum gen nov, sp nov: proposed nomenclature for the human T (T-strain) mycoplasmas. Int J Syst Bacteriol 1974;24:160-71.

${ }^{8}$ Shepard MC, Lunceford CD. Serological typing of Ureaplasma urealyticum isolates from urethritis patients by an agar growth inhibition method. J Clin Microbiol $1978 ; 8: 566-74$.

${ }^{9}$ Shepard MC, Lunceford CD. A differential agar medium (A7) for identification of Ureaplasma urealyticum (human T-mycoplasmas) in primary cultures of clinical material. J Clin Microbiol 1976;3:613-25.

${ }^{10}$ Shepard MC, Lunceford CD. Urease color test medium U-9 for the detection and identification of T-mycoplasmas in clinical material. Appl Microbiol 1970;20:539-43.

${ }^{11}$ Shepard MC. The recovery of pleuropneumonia-like organisms from negro men with and without nongonococcal urethritis. Am J Syph Gonorrhea Vener Dis 1954; 38:113-24.

${ }^{12}$ Bowie WR, Alexander ER, Floyd JF, Holmes J, Miller Y, Holmes KK. Differential response of chlamydial and ureaplasma-associated urethritis to sulphafurazole (sulfisoxazole) and aminocyclitols. Lancet 1976;ii: 1276-8.

${ }^{13}$ Coufalik ED, Taylor-Robinson D, Csonka GW. Treatment of nongonococcal urethritis with rifampicin as a means of defining the role of Ureaplasma urealyticum. $\mathrm{Br} \mathrm{J}$ Vener Dis 1979;55:36-43.

14 Taylor-Robinson D, Csonka GW, Prentice MJ. Human intraurethral inoculation of ureaplasmas. $Q J$ Med 1977;46:309-26.

15 Black FT. Serological methods for classification of human T-mycoplasmas. In 5th International Congress on Infectious Diseases, Vol 1. Vienna, 1970:407-11.

${ }^{16}$ Piot P. Distribution of eight serotypes of Ureaplasma urealyticum in cases of non-gonococcal urethritis and of gonnorrhea, and in healthy persons. Br J Vener Dis 1976;52:266-8.

17 Piot P. Comparison of growth inhibition and immunofluorescence tests in serotyping clinical isolates of Ureaplasma urealyticum. Br J Vener Dis 1977;53:186-9.

${ }^{18}$ Kenny GE. Preparation of antigens and immunogens. In: Barile MF, Razin S, eds. The Mycoplasmas Vol 1. New York: Academic Press, 1979:352-6.

Requests for reprints to: $\mathrm{Dr} \mathrm{H}$ Turunen, Institute of Biomedical Sciences, University of Tampere, Box 607, SF-33101 Tampere 10, Finland. 